\title{
Industry 4.0 for Thai SMEs: Implementing Open Innovation as Innovation Capability Management
}

\author{
Phaninee Naruetharadhol ${ }^{1,3}$, Wutthiya A. Srisathan ${ }^{1,3}$, Nathatenee Gebsombut ${ }^{1}$, Peerapong \\ Wongthahan ${ }^{2}$, Chavis Ketkaew ${ }^{1,3 *}$ \\ 1 International College, Khon Kaen University, 123 Mitrphap Rd., Muang, Khon Kaen, 40002 Thailand \\ 2Innovation and Applied Science division, International College, Khon Kaen University, 123 Mitrphap Rd., \\ Muang, Khon Kaen, 40002 Thailand \\ ${ }^{3}$ Center for Sustainable Innovation and Society, Khon Kaen University, Khon Kaen, Thailand 40002
}

\begin{abstract}
The challenges of cooperation and collaboration faced by small and medium-sized enterprises (SMEs) in Thailand require a specific approach to creating new shared value through innovation-open innovation is extensively applied. The purpose of this research is to shape the psychometric properties of an Open Innovation Implementation scale that supports a fourdimensional factor model incorporating centralization, knowledge management, the technology transfer evaluation process, and networks. A sample of 373 SMEs was used for second-order analysis. The results provided evidence indicating the significant relationship between shaping the concept of Open Innovation Implementation (OII), implying that SMEs should therefore consider the managerial and organizational dimensions of implementing open innovation. In addition, our findings offer manufacturing SMEs the strategic opportunity to innovate via interaction with relevant stakeholders, such as industries, universities, government, and customers/users, to stay competitive.
\end{abstract}

Keywords: Centralization; Industry 4.0; Innovation capability management; Open innovation implementation (OII); Technology transfer evaluation process

\section{Introduction}

The application of science, technology, and innovation is vital to Industry 4.0 in small and medium-sized enterprises (SMEs). The main aim of the cooperation between technology and innovation is to increase firms' innovativeness and productivity (Masood and Sonntag, 2020). Most SMEs do not have sufficient resources or the knowledge capacity (i.e., in domains such as talent and budgeting) to invest in technological innovation and R\&D. This then creates difficulties for SME businesses by preventing them from implementing business innovation models. Consequently, there is a need for innovation. There are two types of innovation: closed and open. The traditional method of achieving innovation-i.e., closed innovation-is through a firm's own R\&D division. It entails the firm strictly keeping the developed intellectual property out of external reach. However, closed innovation requires a huge level of investment and employment to supply the internal R\&D. In contrast, the concept that goes against closed innovation is open innovation (Chesbrough, 2003), which is the process by which ideas and knowledge are

*Corresponding author's email: chaket@kku.ac.th, Tel.: +66-43-202173

doi: 10.14716/ijtech.v13i1.4746 
exchanged between business-industrial partners, universities, users and customers, and public institutions. In its essence, Industry 4.0 refers to the growing trend toward automation and data exchange in manufacturing technology and processes (Xu et al., 2018). Technology helps solve problems and track processes while also improving efficiency and productivity. Therefore, Industry 4.0 is premised on open innovation and digital transformation. Due to innovation capabilities and absorptive capacities to innovative concept, SMEs not only need to adapt and innovate in terms of their products but also improve their manufacturing practices and reduce their environmental footprint across the whole process (Choudhary et al., 2019). This is thus the idea behind integrating open innovation via Industry 4.0. Thailand's Industry 4.0 policy emphasizes manufacturing and production that uses innovation. This policy initiative has specifically targeted five sections within technology and industry: biotechnology; wellness and medical technology; smart devices and machines; food and agriculture; and digital systems and artificial intelligence. Within Thailand's 4.0 policy, Industry 4.0 specifically takes on the role of transforming to digital industrial manufacturing systems. It also connects different strategic partners via the Internet of Things (IoT) to meet more diverse needs. However, Industry 4.0 enhances innovation capabilities through the possibilities of new emerging technologies in manufacturing and production. Recently, the National Innovation Agency (NIA) proposed funding programs for Thai SMEs and start-ups through collaborative partnerships to develop a variety of innovations. All of these factors point to Thailand as the location for the current research.

To the best of our knowledge, there are relatively few prior studies regarding the implementation of open innovation in SMEs specifically quantifying how it is implemented-that is, no empirical evidence has yet been obtained demonstrating how firms implement OI internally. Still, there exists a considerable body of literature on the implementation of the emerging management paradigm of open innovation. Chiaroni et al. (2010; 2011) proposed four managerial levers within Lewin's change model to understand how manufacturing corporations shift from closed innovations: organizational structure, knowledge management, the evaluation process, and networks. These four organizational and managerial systems responded to the Open Innovation Implementation. However, both studies focus on large corporations, the organizational and managerial levers of which may not align with those of SMEs. Gimenez-Fernandez et al. (2021) argued that gamification is an element used to overcome organizational inertia in Open Innovation Implementation, specifically focusing on barriers to open innovation. Naruetharadhol et al. (2020) found that organizational structure, knowledge management, and networks are related to implementing open innovation. They emphasized decentralization, organism, and mechanism; however, centralization appears to be more consistent with the characteristics of Thai SMEs. This is because the majority are family businesses in which top management or business owners oversee the delegation of authority, influence, and decision-making. This justifies the study's decision to test centralization rather than decentralization, which is supported by Liao et al. (2011). This study specifically aims to explore financial-related decision activities (e.g., capital budgeting, etc.), which tend to be relied on by business owners when developing a new innovation or enhancing an existing one. This is about centralized decisions. According to Huizingh (2011), the processes of open innovation are relevant to two phenomena. First, the processes lead to open innovation; this is the process of opening up innovation practices that were formerly closed. The second process refers to the practices of open innovation (i.e., how to implement open innovation). This paper explores the first process of open innovation, referring to it here as "Open Innovation Implementation". In doing so, this research undertakes an evaluation of the managerial and 
organizational dimensions to create a new concept-Open Innovation Implementation (OII) - as a second-order model. Accordingly, we pose the following research question: Does a centralized structure, knowledge management, the technology transfer evaluation process, and networks relate to the emerging implementation of open innovation in smalland medium-sized firms? To answer this, it is assumed that the sub-dimensions of a centralized structure, knowledge management, the technology transfer evaluation process, and networks lead to the occurrence of Open Innovation Implementation (H5). Thus, we define the term Open Innovation Implementation (OII) as the recognition of organizational and managerial components in order to establish an openness to collaboration within an innovation activity. Figure 1 shows the proposed conceptual framework, which consists of the sub-hypotheses (H1-H4), for realizing Open Innovation Implementation.

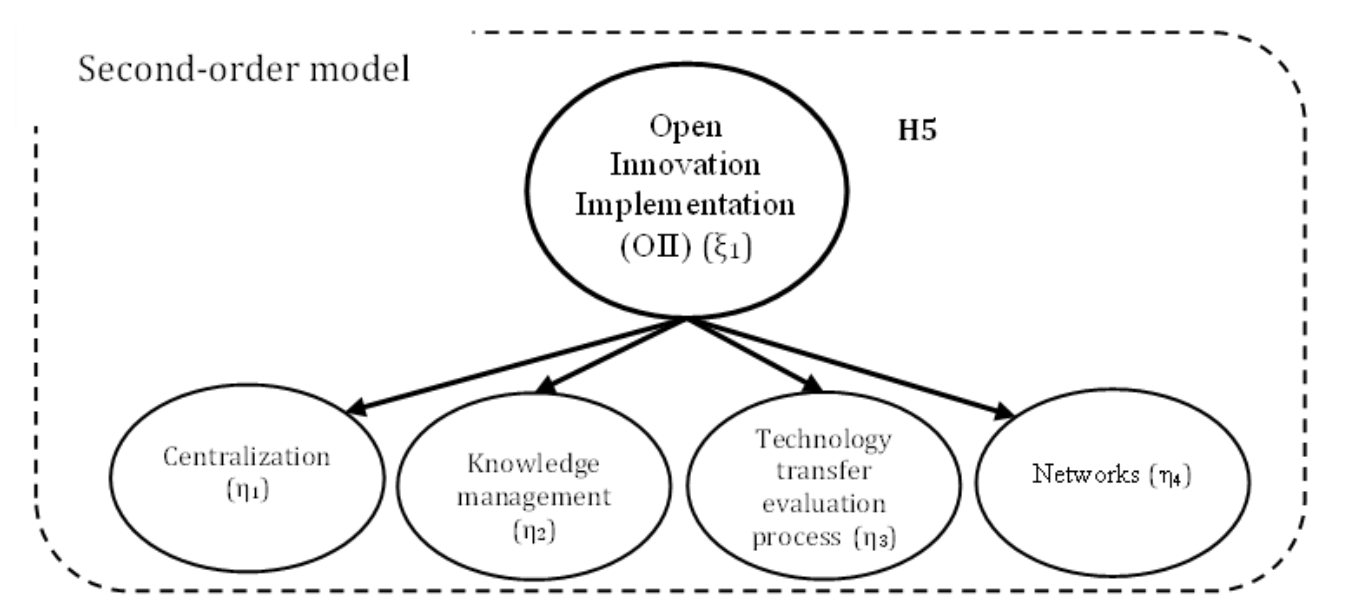

$\mathrm{H} 1(+) ; \lambda_{17} \mid \beta=0.835^{* * *}$

$\mathrm{H} 2(+) ; \lambda_{18} \mid \beta=0.946^{* * *}$

$\mathrm{H} 3(+) ; \lambda_{19} \mid \beta=0.869^{* * *}$

$\mathrm{H} 4(+) ; \lambda_{20} \mid \beta=0.936^{* * *}$

Figure 1 Proposed conceptual framework and second-order model

\section{Methods}

A combination of field and electronic surveys were designed and implemented to collect data. The respondents targeted were business owners, employee-managers, entrepreneurs, CEOs, and other top to middle positions. The DBD Business Data Warehouse was used to identify the whole population $(\mathrm{N}, 433,007)$ of firms that have continued in existence. This figure was as of December 31, 2018. Based on this known population, the minimum sample size (n) was estimated as 384 with a $95 \%$ confidence level (Krejcie and Morgan, 1970). The cluster sampling method was used to collect 800 samples based on geographical region-namely the northern, northeastern, central, eastern, western, and southern regions of Thailand-while purposeful random sampling was used to reach these targets. Our survey was carried out from 2018 to 2019. Of the 800 questionnaires sent out, 636 firms responded, giving a response rate of $79.5 \%(636 / 800=0.795)$. After applying a filter to narrow the data, 373 manufacturing SMEs were further included in the analysis, resulting in a response rate of $46.63 \%(373 / 800=0.4663)$. Sekaran and Bougie (2016, p. 143 ) argued that a $30 \%$ response rate is sufficiently acceptable for a questionnaire survey. These manufacturing SMEs met the inclusion criteria of this study-i.e., firms in the agricultural and food, manufacturing, automotive, equipment, or electronics sectors whose industrial-related activities are linked to the Internet of Things.

\section{Results and Discussion}

To test the research hypothesis, we performed several stages of statistical analysis and constructed various measurement models, including descriptive statistics, the variance 
inflation factor, convergent validity, and discriminant validity. Figure 2 exhibits the descriptive statistics and types of manufacturing SMEs. The analysis revealed that 110 of the 373 respondent firms had received at least one form of government innovation support. Small-size and domestic upstream firms (e.g., paper-making and transportation) represented the smallest proportion in this regard, with $4.29 \%$ and $5.36 \%$ of these firms receiving support, respectively. Convergent validity indicated that the indicators of each construct were valid for measuring the instrument in a related question, as the factor loadings, $\mathrm{y}_{1}-\mathrm{y}_{16}$, exceeded the recommended value of $70 \%$ or 0.7 and were statistically significant $(\mathrm{p}<0.001)$. A measure of the degree of variance captured by each construct showed that each average variance extracted (AVE) was higher than $50 \%$ or 0.5 . Like Cronbach's alpha $(\alpha)$, composite reliability (CR) measures the internal consistency in scale items, and their results surpassed the reasonable threshold of $70 \%$ or 0.7 . Moreover, this paper detected multicollinearity issues using variance inflation factors (VIFs) (see Table 1) and discriminant validity. The result of VIFs less than 10 did not signal multicollinearity (O'Brien, 2007). The HTMT of the correlations (to assess the discriminant validity) was less than the threshold of 0.90 (Henseler et al., 2014), confirming no degree of similarity between the latent variables in this research (see Table 2). Thus, these analyses led to further analysis of the measurement model. The model fit indices for the first-order measurement model are shown in Table 3, which suggests a good fit of all the indices (Hair et al., 2010). Overall, the results demonstrated that the proposed indicators could wellcapture the constructs and allowed us to evaluate and interpret the hypothesized model, which we will discuss in the next section.

\subsection{Proposed Model Analysis}

The purpose of this paper was to perform a second-order model analysis on the effect of the organizational and managerial dimensions on implementing open innovation in manufacturing SMEs. Key studies (e.g., Chiaroni et al., 2010; 2011) and Naruetharadhol et al., 2020) were included in the formation and development of this concept paper. The results indicated that the hierarchical component model (HCM) of Open Innovation Implementation ( $\xi 1)$ was statistically related to the four organizational and managerial dimensions (i.e., centralized structure, knowledge management, the technology transfer evaluation process, and networks) - thus accepting the alternative hypotheses - with a moderate-to-strong relationship. We then aimed to assess these four managerial and organizational aspects using a seven-point Likert rating scale, with 7 denoting strongly agree and 1 denoting strongly disagree. Table 1 shows the scale items of the variables of interest. The hierarchical second-order model enabled us to model the heterogeneous data across the 373 small firms. These phenomena are further discussed within the framework summarizing the relationship between the structural variables in the following four propositions:

Proposition 1. Centralization relates to the implementation of small firms' open innovation with the equation: $\eta_{1}=\lambda_{17} \xi_{1}+\zeta_{1}$, where $y_{1}=\alpha_{1}+\lambda_{1} \eta_{1}+\varepsilon_{1} ; y_{2}=\alpha_{2}+$ $\lambda_{2} \eta_{1}+\varepsilon_{2} ; y_{3}=\alpha_{3}+\lambda_{3} \eta_{1}+\varepsilon_{3}$; and $y_{4}=\alpha_{4}+\lambda_{4} \eta_{1}+\varepsilon_{4}$. For the discussion of the results below, it is useful to understand that the latent second-order dimension of Open Innovation Implementation is explained by the first-order dimension of centralization, which is measured by the indicators $\mathrm{y}_{1}$ to $\mathrm{y}_{4}$. The indication implies that centralization activities give importance to the introduction of new product/service innovation (CT1: $\mathrm{y}_{1}$ ); capital budgeting (CT2: $\mathrm{y}_{2}$ ); a set of pricing policies (CT3: $\mathrm{y}_{3}$ ); and entrance into a new market with a new market strategy (CT4: $\mathrm{y}_{4}$ ). These four items were adapted from Liao et al. (2011). The business unit has more incentives, because manufacturing SMEs use business models to influence the needs for changing structures and systems by taking modern technological 
ideas and knowledge from outside firms to capture the additional benefits from conducting research.

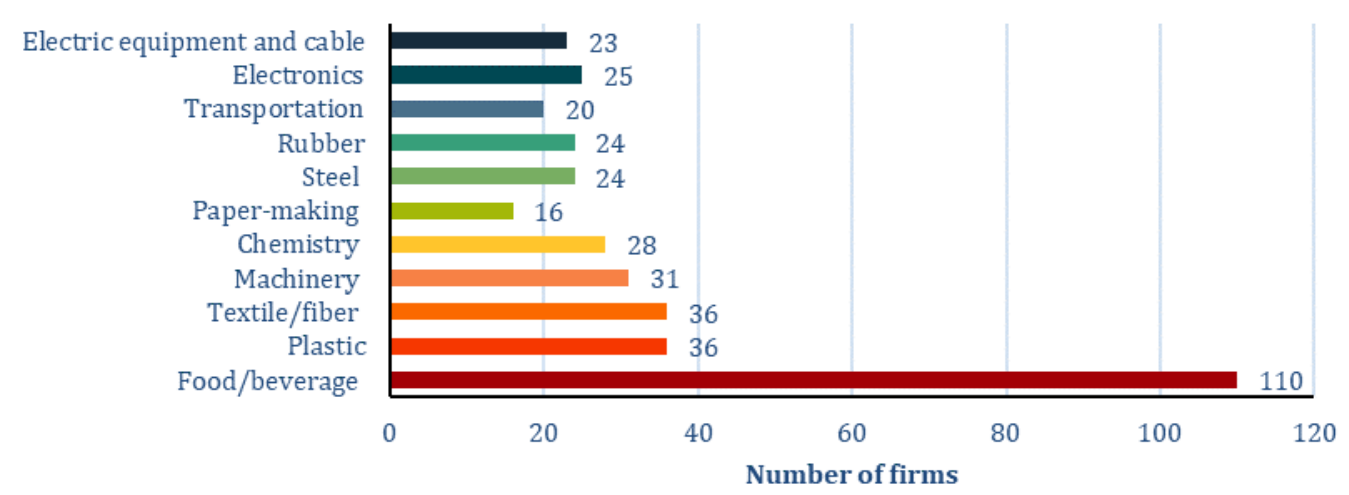

Figure 2 Sample characteristics by type of manufacturing SME

Table 1 Construct validity and reliability

\begin{tabular}{|c|c|c|c|c|c|c|}
\hline Constructs & Scale items & $\Lambda$ & AVE & CR & $\alpha$ & VIF \\
\hline $\begin{array}{l}\text { Open Innovation } \\
\text { Implementation (OII) }\end{array}$ & & & 0.769 & 0.929 & - & - \\
\hline \multirow{4}{*}{ Centralization } & CT4 ... the introduction of new product/service innovation & 0.733 & & & & 2.075 \\
\hline & CT3 ... set of pricing policies & 0.78 & & & & 2.732 \\
\hline & CT2 ... capital budgeting & 0.816 & & & & 2.618 \\
\hline & CT1 ... entrance to a new market with new market strategy & 0.744 & 0.591 & 0.852 & 0.852 & 2.165 \\
\hline \multirow{4}{*}{$\begin{array}{l}\text { Knowledge } \\
\text { management }\end{array}$} & KM4 ... talent and expert acquisition & 0.823 & & & & 2.123 \\
\hline & KM3 ... intellectual property management & 0.763 & & & & 2.584 \\
\hline & $\begin{array}{l}\text { KM2 ... information technology management systems (e.g., } \\
\text { Industrial Internet of Things) }\end{array}$ & 0.813 & & & & 2.770 \\
\hline & $\begin{array}{l}\text { KM1 ... know-how related to the market (e.g., regulators, } \\
\text { competitors, supplies, customers) }\end{array}$ & 0.815 & 0.646 & 0.879 & 0.877 & 1.499 \\
\hline \multirow{4}{*}{$\begin{array}{l}\text { Technology transfer } \\
\text { evaluation process }\end{array}$} & TTE4 ... search for different kinds of technological partners & 0.577 & & & & 2.985 \\
\hline & $\begin{array}{l}\text { TTE3 ... evaluation of knowledge-assets for their } \\
\text { commercialization in the market }\end{array}$ & 0.799 & & & & 2.941 \\
\hline & TTE2 ... preparation of intellectual property registration & 0.783 & & & & 2.392 \\
\hline & $\begin{array}{l}\text { TTE1 ... the evaluation process of technological knowledge } \\
\text { acquisition and licensing (e.g., a patent, industrial design right, } \\
\text { copyright) to create/improve (new) innovations as a basis for } \\
\text { using something already existing }\end{array}$ & 0.727 & 0.528 & 0.815 & 0.807 & 3.096 \\
\hline \multirow{4}{*}{ Networks } & $\begin{array}{l}\text { NWK4 ... industries (e.g., other firms within the business } \\
\text { group or suppliers) }\end{array}$ & 0.734 & & & & 2.242 \\
\hline & NWK3... customers & 0.786 & & & & 2.994 \\
\hline & NWK2 ... universities & 0.796 & & & & 2.551 \\
\hline & NWK1... public/governmental institutions & 0.719 & 0.577 & 0.845 & 0.842 & 2.160 \\
\hline
\end{tabular}

Table 2 Heterotrait-Monotrait Ratio of Correlations (HTMT)

\begin{tabular}{ccccc}
\hline & NWK & TTE & KM & CT \\
\hline NWK & & & & \\
TTE & 0.814 & & & \\
KM & 0.886 & 0.823 & & \\
CT & 0.782 & 0.726 & 0.79 & \\
\hline
\end{tabular}

Table 3 Overall measurement model indices

\begin{tabular}{lccccccc}
\hline \multicolumn{1}{c}{ Fit Indices } & CMIN/df & RMR & GFI & TLI & CFI & RMSEA & PCFI \\
\hline First-order CFA & 1.944 & 0.044 & 0.938 & 0.968 & 0.974 & 0.05 & 0.795 \\
Second-order CFA & 1.996 & 0.046 & 0.935 & 0.966 & 0.972 & 0.052 & 0.81 \\
Thresholds & $<3.00$ & $<0.08$ & $>0.90$ & $>0.90$ & $>0.90$ & $<0.08$ & $>0.50$ \\
\hline
\end{tabular}


Table 4 Regression paths for the second-order model

\begin{tabular}{cllcccc}
\hline $\mathrm{H}$ & \multicolumn{2}{c}{ Relationships } & Estimates $(\lambda)$ & $\mathrm{R}^{2}$ & $p$ & Results \\
\hline $\mathrm{H} 1$ & Centralized structure & $\begin{array}{l}\text { Open Innovation } \\
\text { Implementation }\end{array}$ & 0.835 & 0.697 & $* * *$ & Accepted \\
\hline $\mathrm{H} 2$ & $\begin{array}{l}\text { Knowledge } \\
\text { management }\end{array}$ & $\begin{array}{l}\text { Open Innovation } \\
\text { Implementation }\end{array}$ & 0.946 & 0.895 & $* * *$ & Accepted \\
\hline $\mathrm{H} 3$ & $\begin{array}{l}\text { Technology transfer } \\
\text { evaluation process }\end{array}$ & $\begin{array}{l}\text { Open Innovation } \\
\text { Implementation }\end{array}$ & 0.869 & 0.755 & $* * *$ & Accepted \\
\hline $\mathrm{H} 4$ & Networks & $\begin{array}{l}\text { Open Innovation } \\
\text { Implementation }\end{array}$ & 0.936 & 0.876 & $* * *$ & Accepted \\
\hline H5 & $\mathrm{H} 1, \mathrm{H} 2, \mathrm{H} 3, \mathrm{H} 4$ & $\begin{array}{l}\text { Open Innovation Implementation is relatively } \\
\text { explained by the dimensions of centralized structure, } \\
\text { knowledge management systems, technology transfer } \\
\text { evaluation, and networks. }\end{array}$ & Accepted \\
\hline Note: $p=\mathrm{p}$-value; $* * *=<0.001$ & & & & \\
\hline
\end{tabular}

Proposition 2. Knowledge management relates to the implementation of small firms' open innovation with the equation: $\eta_{2}=\lambda_{18} \xi_{1}+\zeta_{2}$, where $y_{5}=\alpha_{5}+\lambda_{5} \eta_{2}+\varepsilon_{5} ; y_{6}=$ $\alpha_{6}+\lambda_{6} \eta_{2}+\varepsilon_{6} ; y_{7}=\alpha_{7}+\lambda_{7} \eta_{2}+\varepsilon_{7} ;$ and $y_{8}=\alpha_{8}+\lambda_{8} \eta_{2}+\varepsilon_{8}$. The thrust of Proposition 2 is that, in order to implement knowledge management systems for open innovation, the partner whose effort is more essential has to favor the introduction of the new innovation management. We adapted and modified variables designed by Boadu et al. (2018) and Chiaroni et al. (2011) to measure knowledge management in the context of explicit and tacit knowledge transfer. The indicators $\mathrm{y}_{5}-\mathrm{y}_{8}$ assume that SMEs need to start considering knowhow related to the market (e.g., regulators, competitors, supplies, customers) (KM1: y5$_{5}$; information technology management systems (e.g., Industrial Internet of Things) (KM2: $\mathrm{y}_{6}$ ); intellectual property management (KM3: $\mathrm{y}_{7}$ ), and talent and expert acquisition (KM4: $\mathrm{y}_{8}$ ). Knowledge management (KM) is important in supporting the shift towards practices of open innovation, as its concept of open innovation facilitates the use of digital technology, IT tools, platforms, and applications, and the adoption of intellectual property (e.g., patents).

Proposition 3. The technology-transfer evaluation process relates to the implementation of small firms' open innovation with the specification: $\eta_{3}=\lambda_{19} \xi_{1}+\zeta_{3}$ where $y_{9}=\alpha_{9}+$ $\lambda_{9} \eta_{3}+\varepsilon_{9} ; y_{10}=\alpha_{10}+\lambda_{10} \eta_{3}+\varepsilon_{10} ; y_{11}=\alpha_{11}+\lambda_{11} \eta_{3}+\varepsilon_{11} ;$ and $y_{12}=\alpha_{12}+\lambda_{12} \eta_{3}+$ $\varepsilon_{12}$. In Proposition 3 , we define this term as the process by which firms evaluate an exchange of ideas, know-how, discovery, intellectual property, technical knowledge, or inventions arising from university- or industry-sponsored scientific research in order to implement new/existing innovations. The indicators $\mathrm{y}_{9}-\mathrm{y}_{12}$ are attributed to the evaluation process of technological knowledge acquisition and licensing (e.g., patents, industrial design rights, copyrights) to create/improve (new) innovations as a basis for using something already existing (TT1: y9); prepare intellectual property registration (TT2: y10);

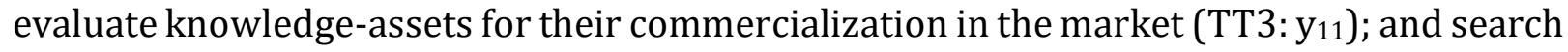
for different kinds of stakeholders (TT4: $\mathrm{y}_{12}$ ). The four-item scale was adapted from Chiaroni et al. (2011) and Hung and Chou (2013) and was also self-developed. In such circumstances, manufacturing firms need to configure decision rights, reduce risk, and increase the chance at benefits. They require the evaluation process of technology transfer to direct most of their attention to exploitation paths of innovation through the strategic use of corporate venture capital (CVC).

Proposition 4. Networks relate to the implementation of small firms' open innovation given the specification of the equation model: $\eta_{4}=\lambda_{20} \xi_{1}+\zeta_{4}$, where $y_{13}=\alpha_{13}+\lambda_{13} \eta_{4}+$ $\varepsilon_{13} ; y_{14}=\alpha_{14}+\lambda_{14} \eta_{4}+\varepsilon_{14} ; y_{15}=\alpha_{15}+\lambda_{15} \eta_{4}+\varepsilon_{15} ;$ and $y_{16}=\alpha_{16}+\lambda_{16} \eta_{4}+\varepsilon_{16}$. Considering the search depth and breadth of manufacturing SMEs' innovation networks, 
Proposition 4 states that the demonstration of matchmaking between collaborative networks. In the Quadruple Helix model, users and customers are key to the development of an innovation-that is, they will tend to accept and use the innovation. The indicators $\mathrm{y}_{13}-\mathrm{y}_{16}$ measure the representatives from industries and suppliers (NWK1: $\mathrm{y}_{13}$ ); customers

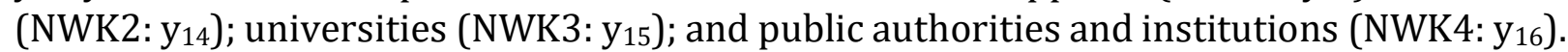
These four-network items were adapted from Ferreras-Méndez et al. (2015). Digital technological innovations for Industry 4.0 help promote cooperation between stakeholders to demonstrate innovative solutions, especially to gain support from the government and consumers (Tatiana and Mikhail, 2020).

\subsection{Empirical Results and Implications}

The results of the empirical analysis provided support for the hypothesized model (see Table 4). The arrows of the loadings, $\lambda_{17}$ to $\lambda_{20}$, are reversed to reflect the centralization, knowledge management, technology transfer evaluation process, and networks comprising Open Innovation Implementation, confirming Hypothesis 5. A diagrammatic framework of this model is exhibited in Figure 1.

Hypothesis 1 , testing that centralization explained Open Innovation Implementation $(\beta$ $\left.=0.835 ; r^{2}=0.697 ; \mathrm{P}<0.001\right)$, was accepted. This finding is slightly different from the result of Naruetharadhol et al. (2020), which indicated firms' structure and systems need to authorize work procedures, decision power, rules, and policies to collaborate with external parties suitably. However, this seems to agree with larger corporations' systems compared to small firms. This also seems to correspond well with some flexible activities, such as marketing-related decision activities or knowledge development activities, at local unit (Liao et al., 2011). The current research findings show that centralization created the information flow and decision-making authorities (i.e., the importance of the introduction of new product/service innovations, capital budgeting to develop an innovation, pricing policies, and entrance to a new market with a new market strategy) and then affected innovation performance. Centralization would allow make the organization more willing to accept innovation initiatives for its firm structure, culture, and systems (Naruetharadhol et al., 2021).

Hypothesis 2, which tested the influence of knowledge management on Open Innovation Implementation, was confirmed $\left(\beta=0.946 ; \mathrm{r}^{2}=0.895 ; \mathrm{P}<0.001\right)$. This finding suggests that knowledge management plays an important role in innovation and human resource management. The core considerations for knowledge management systems are placed on people, technology, structure, culture, processes, and technology. During Open Innovation Implementation, SMEs should keep in mind how they would manage both the existing and new knowledge base of the firm.

Hypothesis 3 tested open innovation is explained by the technology transfer evaluation process. The strength of their link provided confirmatory evidence $\left(\beta=0.869 ; r^{2}=0.755 ; P\right.$ $<0.001$ ). This finding implies that small firms could open up their innovation process via a technology-based strategy. The main way in which open innovation provides a solution for SMEs is that that it allows them to have an evaluative interaction between technology push and market pull and then prepare for new technology commercialization models and transfer procedures.

Hypothesis 4 indicates networks significantly explain Open Innovation Implementation $\left(\beta=0.936 ; r^{2}=0.876 ; P<0.001\right)$. This implies that manufacturing SMEs could gain a variety of knowledge and technology sources from external partners. Besides, the key actors of innovation-generating processes (e.g., industries, universities, government, and users) collaborate to facilitate the transfer of research and innovation results. A user-centric product/service design and $R \& D$ effort help to develop the 
innovation solution to enhance the interaction between the product/service provider and its customers (Romijn and Albaladejo, 2002).

Open innovation is realized as an enabler of innovation that develops internal managerial and innovation capabilities to enthusiastically support the effects of open innovation strategies. In particular, an open approach to innovation fosters knowledge management capabilities, which, in turn, improves an open innovation strategy's efficiency (Santoro et al., 2018). This confirms the expansion of firms' boundaries and suggests that open innovation may present a number of opportunities for expanding markets, commercializing new or improved innovations (e.g., products, services, processes), and exploring new knowledge. This is how small businesses can use open innovation to manage their innovation capabilities. Hence, innovation capabilities requires the consideration of knowledge management, internal organizational development, networks, and technology transfer management. Our findings suggest that manufacturing SMEs should consider the four-dimensional measures of OII as an analytical tool to help implement: (1) a new balance of physical and digital knowledge and resources to harness open innovation and add value to science (Bogers et al., 2018); and (2) disruptive innovation technologies (e.g., augmented reality (AR), big data and predictive analysis, predictive maintenance, cybersecurity, cloud computing, and additive manufacturing), leading to an overall shift toward Industry 4.0 (Mariani and Borghi, 2019). The role of Industry 4.0 is important for implementing sustainable development goals (SDGs), a key issue Thailand plans to highlight in its national plan. The Industrial Internet of Things will allow data to become valuable knowledge, which will further improve innovation and productivity performance (Berawi, 2018). Based on our evidence and exploration, Thai policymakers should embrace the transfer of information and communication technology (e.g., Industrial Internet of Things) to realize the transition toward a value-based economy-as required under Thailand 4.0 implementation - in which community supplies raise the value of products and services. A specific innovation strategy existing from the results of this research (NWK 2-3) is strategic cooperative and collaborative orientation with customers and universities. These strategies will enable industrial manufacturing's most innovative SMEs to go well beyond codeveloping product and service innovations - that is, SMEs can gain a major competitive advantage by accessing faster, better, and cheaper innovation sources.

\section{Conclusions}

Open innovation may not be the best-for-all strategic innovation management for SMEs, but it provides an integral dimension to existing innovation approaches and accelerates collaborative learning and value development (i.e., like a wave raises all boats). This study develops and proposes a new theoretical concept of Open Innovation Implementation (OII) for small business practitioners and scholars. Accordingly, this current research answers the holistic question of how centralized structure, knowledge management, technology transfer evaluation, and networks relate to the emerging implementation of open innovation in small- and medium-sized firms. While this paper uses an aggregated data statistical method to empirical model, further research could be conducted based on the manufacturing profile and clustering. Applying the multigroup mean structures model of covariance-based SEM makes the research model more general in terms of smart manufacturing-industrial implementations, expanding the examples of the research model. Furthermore, future studies could also investigate whether this theoretical model of Open Innovation Implementation, as a basic theory, can be applied to the other industry types of the remaining 263 SMEs (e.g., trading, service, etc.) and the effects that it may have on the persistence of SMEs to commit to 
adopting an open innovation environment.

\section{Acknowledgements}

This work was financially supported by the International College, Khon Kaen University, Thailand. Also, authors would like to sincerely thank to Ms. Sasichakorn Wongsaichia for her vulnerable support in data collection.

\section{References}

Berawi, M.A., 2018. Utilizing Big Data in Industry 4.0: Managing Competitive Advantages and Business Ethics. International Journal of Technology, Volume 9(3), pp. 430-433

Boadu, F., Xie, Y., Du, Y.F., Dwomo-Fokuo, E., 2018. MNEs Subsidiary Training and Development and Firm Innovative Performance: The Moderating Effects of Tacit and Explicit Knowledge Received from Headquarters. Sustainability, Volume 10(11), pp. 125

Bogers, M., Chesbrough, H., Moedas, C., 2018. Open Innovation: Research, Practices, and Policies. California Management Review, Volume 60(2), pp. 5-16

Chesbrough, H.W., 2003. Open Innovation: The New Imperative for Creating and Profiting from Technology. Harvard Business School Press

Chiaroni, D., Chiesa, V., Frattini, F., 2010. Unravelling the Process from Closed to Open Innovation: Evidence from Mature, Asset-Intensive Industries. R\&D Management, Volume 40(3), pp. 222-245

Chiaroni, D., Chiesa, V., Frattini, F., 2011. The Open Innovation Journey: How Firms Dynamically Implement the Emerging Innovation Management Paradigm. Technovation, Volume 31(1), pp. 34-43

Choudhary, S., Nayak, R., Dora, M., Mishra, N., Ghadge, A., 2019. An Integrated Lean and Green Approach for Improving Sustainability Performance: A Case Study of a Packaging Manufacturing SME in the U.K. Production Planning \& Control, Volume 30(5-6), pp. 353-368

Ferreras-Méndez, J.L., Newell, S., Fernández-Mesa, A., Alegre, J., 2015. Depth and Breadth of External Knowledge Search and Performance: The Mediating Role of Absorptive Capacity. Industrial Marketing Management, Volume 47, pp. 86-97

Gimenez-Fernandez, E., Abril, C., Breuer, H., Gudiksen, S., 2021. Gamification Approaches for Open Innovation Implementation: A Conceptual Framework. Creativity and Innovation Management, Volume 30(3), pp. 455-474

Hair, J.F., Black, W.C., Babin, B.J., Anderson, R.E., 2010. Multivariate Data Analysis. 7th ed, Pearson Education: Upper Saddle River, New Jersey.

Henseler, J., Ringle, C.M., Sarstedt, M., 2014. A New Criterion for Assessing Discriminant Validity in Variance-Based Structural Equation Modeling. Journal of the Academy of Marketing Science, Volume 43(1), pp. 115-135

Huizingh, E.K.R.E., 2011. Open Innovation: State of the Art and Future Perspectives. Technovation, Volume 31(1), pp. 2-9

Hung, K.P., Chou, C., 2013. The Impact of Open Innovation on Firm Performance: The Moderating Effects of Internal R\&D and Environmental Turbulence. Technovation, Volume 33(10-11), pp. 368-380

Krejcie, R.V., Morgan, D.W., 1970. Determining Sample Size for Research Activities. Educational and Psychological Measurement, Volume 30(3), pp. 607-610

Liao, C., Chuang, S.H., To, P.L., 2011. How Knowledge Management Mediates the Relationship Between Environment and Organizational Structure. Journal of Business 
Research, Volume 64(7), pp. 728-736

Mariani, M., Borghi, M., 2019. Industry 4.0: A Bibliometric Review of Its Managerial Intellectual Structure and Potential Evolution in the Service Industries. Technological Forecasting and Social Change, Volume 149, https://doi.org/10.1016/j.techfore.2019.119752

Masood, T., Sonntag, P., 2020. Industry 4.0: Adoption Challenges and Benefits for SMEs. Computers in Industry, Volume 121, https://doi.org/10.1016/j.compind.2020.103261

Naruetharadhol, P., Srisathan, W.A., Ketkaew, C., 2020. The Effect of Open Innovation Implementation on Small Firms' Propensity for Inbound and Outbound Open Innovation Practices. Frontiers in Artificial Intelligence and Applications, Volume 329, pp. $30-40$

Naruetharadhol, P., Srisathan, W.A.W.A., Suganya, M., Jantasombut, J., Prommeta, S., Ketkaew, C., 2021. Organizational Commitment and Engagement Practices from Applying Green Innovation to Organizational Structure: A Case of Thailand Heavy Industry. International Journal of Technology, Volume 12(1), pp. 22-32

O’Brien, R.M., 2007. A Caution Regarding Rules of Thumb for Variance Inflation Factors. Quality and Quantity, Volume 41(5), pp. 673-690

Romijn, H., Albaladejo, M., 2002. Determinants of Innovation Capability in Small Electronics and Software Firms in Southeast England. Research Policy, Volume 31(7), pp. 10531067

Santoro, G., Vrontis, D., Thrassou, A., Dezi, L., 2018. The Internet of Things: Building a Knowledge Management System for Open Innovation and Knowledge Management Capacity. Technological Forecasting and Social Change, Volume 136, pp. 347-354

Sekaran, U., Bougie, R., 2016. Research Methods for Business: A Skill-Building Approach (7th ed.). John Wiley \& Sons

Tatiana, B., Mikhail, K., 2020. Problems of Competitive Strategy Choice According to Industry and Regional Factors. International Journal of Technology, Volume 11(8), pp. 1478-1488

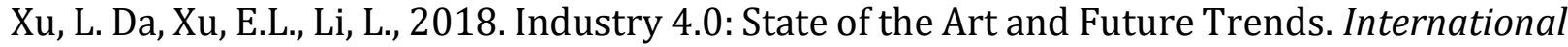
Journal of Production Research, Volume 56(8), pp. 2941-2962 